\title{
MARÍA CECILIA COLOMBANi
}
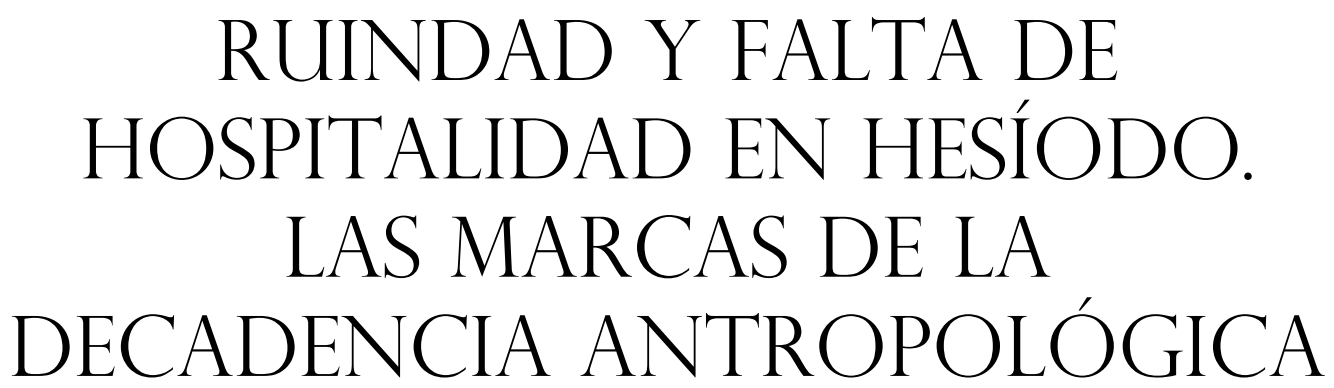

\section{MEANNESS AND INHOSPITALITY IN HESIOD'S WORK. THE TRACES OF ANTHROPOLOGICAL DECADENCE}

ceciliacolombani@hotmail.com

Recepción: 10/08/2021

Aceptación: 26/11/2021

\section{RESUMEN}

En este artículo trabajaremos sobre las marcas de la hospitalidad que aparecen en la obra de Hesíodo así como sobre las actitudes que se oponen a tal dimensión espiritual, emparentada con la virtud de excelencia del varón prudente. Entendemos que la hospitalidad está intrínsecamente asociada a la virtud, areté, y al reconocimiento del otro. En términos de M. Buber, la hospitalidad está relacionada con la posibilidad de abrirse a un tú en el umbral del lenguaje; también está vinculada con la experiencia heideggeriana del "ser con" en tanto reconocimiento del par antropológico, o con la propia experiencia antropológica que define al personalismo de E. Mounier en el reconocimiento y respeto de la persona humana.

\section{PALABRAS CLAVE}

Hospitalidad, Reconocimiento, Respeto, Otro.

\section{ABSTRACT}

In this article, we will work on the marks of hospitality that appear in Hesiod's work as well as on the attitudes that oppose such a spiritual dimension, related to the virtue of excellence of the prudent man. We understand that hospitality is intrinsically associated with virtue, areté, and the recognition of the other. In terms of M. Buber, hospitality is related to the possibility of opening up to a "you" on the threshold of language; it is also linked to the Heideggerian experience of "being with" as recognition of the anthropological pair, or with the anthropological experience itself that defines E. Mounier's personalism in the recognition and respect of the human person.

Tábano, no. 18 (2021), 123-128.

DOI: https://doi.org/10.46553/tab.18.2021.p123-128 


\section{KEYWORDS}

Hospitality, Recognition, Respect, Other.

\section{INTRODUCCIÓN}

En este artículo trabajaremos sobre las marcas de la hospitalidad que aparecen en la obra de Hesíodo así como sobre las actitudes que se oponen a tal dimensión espiritual, emparentada con la virtud de excelencia del varón prudente. Entendemos que la hospitalidad está intrínsecamente asociada a la virtud, areté, y al reconocimiento del otro. En términos de M. Buber (1974), la hospitalidad está relacionada con la posibilidad de abrirse a un tú en el umbral del lenguaje; también está vinculada con la experiencia heideggeriana del "ser con" en tanto reconocimiento del par antropológico, o con la propia experiencia antropológica que define al personalismo de E. Mounier (1972) en el reconocimiento y respeto de la persona humana.

Se trata siempre de un estado de apertura, de poder acoger al Otro en su ser; un estado de disponibilidad de asumir al otro en calidad de semejante y abrir parte del ser en un gesto de reciprocidad compartida. El pensamiento griego ha dedicado su inquietud al tópico y podemos considerar la obra de Homero como una verdadera paideia de la hospitalidad.

\section{Desarrollo}

Nuestro intento radica en pensar la contracara de la hospitalidad, es decir el deterioro de la condición antropológica descripta en Trabajos y Días. Creemos que esa decadencia ética está directamente relacionada con la falta de hospitalidad. El perfil del hombre carente de hospitalidad fomenta el clima de injusticia y hostilidad que Hesíodo describe como nudo histórico del tiempo que le toca vivir. El hombre ruin suele estar asociado a las relaciones de poder que se establecen entre quienes mandan y quienes obedecen; no obstante, también podemos advertir las mismas marcas de hostilidad en un territorio más acotado como es el tópos íntimo. En efecto, las relaciones entre parientes y amigos son el escenario perfecto para desplegar teatralmente los valores negativos asociados al hombre carente de hospitalidad.

El padre no se parecerá a los hijos ni los hijos al padre; el anfitrión no apreciará a su huésped ni el amigo a su amigo y no se querrá al hermano como antes. Despreciarán a sus padres apenas se hagan viejos y les insultarán con duras palabras, cruelmente, sin advertir la vigilancia de los dioses -no podrían dar el sustento debido a sus padres ancianos aquellos [cuya justicia es la violencia-, y unos saquearán las ciudades de los otros]. Ningún reconocimiento habrá para el que cumpla su palabra ni para el justo ni el honrado, sino que tendrán más consideración al malhechor y al hombre violento. (Hesíodo, 2005, pp. 182-193) 
Los versos resultan un fiel reflejo de la degradación de los vínculos entre pares y la falta de hospitalidad, núcleo de la virtud. La primera impresión es el vaciamiento de las relaciones familiares y de amistad que dan cuenta de un desconocimiento éticoantropológico del otro como tal. Vaciamiento que da cuenta de la ausencia de deberes y conductas responsables que exige el tipo de vínculo. Hijos que dejan de cumplir su rol de hijos desconociendo la figura del padre; hermanos y amigos que pierden el núcleo íntimo de la relación que debe unirlos.

Podríamos pensar entonces en la relación que asocia al varón que desconoce la hospitalidad con el desconocimiento del otro y que constituye una forma de la injusticia. Los últimos versos ponen de relieve la tensión reconocimiento-desconocimiento, al tiempo que despliegan pares antropológicos antitéticos: el hombre hospitalario que es, a la vez, justo y honrado se opone al hombre ruin e injusto; no obstante, la propia lógica del derrumbe ético-antropológico que el poema devuelve pierde de vista estas clasificaciones que sostienen la arquitectura binaria que Hesíodo propone.

Los dioses han dado la justicia a los hombres para que no se devoren entre sí como los animales ${ }^{1}$ y sepan acoger al otro como semejante en el marco de una lógica reciprocitaria. Este corrimiento de las fronteras entre lo ruin y lo noble constituye una especie de animalización de los mortales que dejan de confiar en la palaba pronunciada y de registrar la distancia entre las distintas clases de hombres como pilar de la constitución de una aldea más justa. A continuación, podríamos detenernos en la relación que vincula al varón carente de hospitalidad con el daño, una nueva forma de injusticia.

La justicia estará en la fuerza de las manos y no existirá pudor; el malvado tratará de perjudicar al más virtuoso con retorcidos discursos y además se valdrá del juramento. La envidia murmuradora, gustosa del mal y repugnante, acompañará a todos los hombres miserables. (Hesíodo, 2005, pp. 193-197)

La ausencia de la palabra como útil antropológico capaz de albergar al otro en gesto hospitalario desencadena la preminencia de la fuerza bestial contra el otro, desconociéndolo sin pudor alguno en su estatuto humano. La soberanía del hombre ruin por sobre el virtuoso trastoca el marco del escenario ético y posiciona a la maldad como eje dominante de las relaciones interpersonales, al tiempo que aleja la condición moral de la hospitalidad.

Los versos dan cuenta de la propia realidad histórica de Hesíodo y de su cercanía vivencial con las prácticas más ruines, alejadas de todo reconocimiento del otro como gesto ético. Tal como señala Mercedes Madrid:

El suyo es un ambiente rural y provinciano de campesinos que tienen que trabajar para subsistir y de una 'clase media' emergente que busca un reconocimiento y lucha por defenderse de las

\footnotetext{
${ }^{1}$ La fábula del halcón y del ruiseñor da cuenta de esta distancia entre los hombres y las bestias y las distintas lógicas que los asisten.
} 
arbitrariedades e injusticias de los nobles 'devoradores de regalos', cuyas sentencias el propio poeta critica tachándolas de "torcidas". (Madrid, 1999, p. 81)

En la misma línea de la constitución del varón político, del anér politikós, arribamos a una relación que vincula al varón ruin con el modelo de subjetividad, en términos de constitución de uno mismo. Las acciones ruines se vuelven siempre contra quien las comete. No se permanece indemne de tal proceder, sino más bien, uno mismo se constituye en su propia víctima. Quien persiste en su desconocimiento del otro alejado de toda posibilidad de albergue relacional, no puede esperar reciprocidad en los vínculos entre pares: "El hombre que trama males para otros, trama su propio mal; y un plan malvado perjudica más a quien lo proyectó" (Hesíodo, 2005, 265-266).

Una nueva relación vincula al varón ruin con la riqueza. Se trata de un tema delicado por las distintas formas de obtener riquezas, las cuales dan cuentan de las distintas categorías de hombres que delinea el poema. El hombre ruin no tiene escrúpulos en la obtención de la riqueza porque básicamente desconoce a su par antropológico y con ello las reglas de la hospitalidad que hacen del mundo un topos habitable. Quizás sea la marca más fina que define su ruindad. El desconocimiento del otro y su incapacidad de hospedarlo en su corazón, se juega en una línea bifronte, ya que no solo ignora antropológicamente a quien le roba, sino también a los dioses que todo lo observan y castigan las acciones malvadas.

Las riquezas no deben robarse; las que dan los dioses son mucho mejores; pues si alguien con sus propias manos quita a la fuerza una gran fortuna o la roba con su lengua como a menudo sucede -cuando el deseo de lucro hace perder la cabeza a los hombres y la falta de escrúpulos oprime la honradez-, rápidamente le debilitan los dioses y arruinan la casa de un hombre semejante, de modo que por poco tiempo dura la dicha. (Hesíodo, 2005, pp. 320-327)

Nítidamente se está cumpliendo la finalidad didáctica del poeta. La descripción y reconocimiento del hombre ruin es una forma de hacer visible una figura de lo Otro, de aquello que atenta contra lo Mismo en términos de conducta ética. Este gesto implica, al mismo tiempo, la incorporación de las formas de la alteridad al campo de la Mismidad. Donar palabra a aquello que resulta indeseable es una forma de conjurarlo y de darle identidad, de afirmar la identidad de lo deseable.

Se trata del momento fundacional de instituir una moral para los hombres a través de una poesía didáctica; una especie de "filosofía popular" que diagrama un campo de fuerzas tensionado entre lo deseable y lo indeseable. Al mismo tiempo, queda perfilado el trazo de una incipiente reflexión moral que hace del hombre ruin el contra-modelo del varón prudente. Son las marcas de una tarea pedagógica en la que Trabajos y Días encuentra su sentido más nítido: "pero el que roba a su antojo obedeciendo a su falta de escrúpulos, lo robado, aunque sea poco, le amarga el corazón” (Hesíodo, 2005, pp. 359-361).

Una nueva relación vincula al varón ruin con los lazos de reciprocidad que él mismo rompe con su conducta, fracturando los nómoi ancestrales, modelos de comportamiento que cohesionan los lazos de philía y las marcas de cohesión social dentro de la aldea. 
Igualmente, el que maltrata a un suplicante o a su huésped, o sube al lecho de su hermano (para unirse ocultamente con su esposa incurriendo en falta), o insensatamente causa daño a los hijos huérfanos de aquél, y el que insulta a su padre anciano, ya en el funesto umbral de la vejez, dirigiéndose a él con duras palabras, sobre éste ciertamente descarga el mismo Zeus su ira y al final en pago por sus injustas acciones le impone un duro castigo. Pero tú aparta por completo tu espíritu de estos delitos. (Hesíodo, 2005, pp. 328-336)

Los versos resultan reveladores a la hora de inteligir el universo relacional que implica la vida. El maltrato, el engaño, el daño, el insulto, el desconocimiento de los deberes como hijo, hermano, anfitrión, amigo, son algunos de los hilos que van bordando el tapiz del hombre ruin, carente de hospitalidad. Podemos inferir el estado de soledad que se genera como consecuencia de la acción moral, ya que el hombre rompe con los distintos vínculos que lo constituyen subjetivamente, y queda incluso desamparado a partir del quiebre con el plano divino.

El hombre ruin se queda solo, más allá de las ilusorias y transitorias ventajas que pueda encontrar en su conducta. El destino es siempre la desdicha. El tipo de vida que venimos relevando se inscribe en una cierta inconstancia, propia de quien actúa sin medir las consecuencias futuras; la referencia a la incapacidad de sostener relaciones de philia duraderas se juega en ese horizonte de sentido, al tiempo que ubica a la hospitalidad como uno de los pilares en la reversión del fenómeno: "Si te empieza él con alguna palabra ofensiva o de obra, recuerda que debes tolerarle otras dos veces; y si vuelve a la amistad y quiere presentarte excusas, acéptalas. El hombre ruin se busca un amigo diferente en cada ocasión”. (Hesíodo, 2005, pp. 710-714)

\section{CONCLUSIONES}

"Si hablas mal, pronto oirás tú peor" (Hesíodo, 2005, p. 720).

El proyecto de la presente reflexión consistió en pensar el perfil del hombre ruin a partir de las marcas que visibiliza Trabajos y Días, rescatando su estatuto de poema paradigmático a la hora de trazar dos registros de hombres de características opuestas. De este modo, la obra resulta una poiesis instituyente de una determinada realidad éticoantropológica. Lo hemos efectuado a la luz de un marco de pensamiento que propone la coexistencia de dos linajes de valencias opuestas, uno positivo, donde la hospitalidad resulta un elemento capital, y otro negativo, donde el desconocimiento del par es la clave de la degradación moral, uno de matriz diurna y otro de matiz nocturna respectivamente, para inteligir la arquitectura del mito como logos explicativo.

Intentamos relevar el valor simbólico del linaje negativo, tópos de inscripción del hombre ruin, alejado de la hospitalidad como modo de abrir el corazón al par. 
Lo hicimos a partir del intento de relevar la construcción que el poema propone a la hora de definir el territorio de conductas y costumbres que la experiencia histórica parece demandar; trazo de una gramática que necesariamente implica dibujar la línea divisoria entre lo Mismo y lo Otro en materia de conducta moral como modo de desplegar e instituir los signos de un modelo de humanidad.

\section{SOBRE LA AUTORA}

Doctora en Filosofía por la Universidad de Morón. Profesora Titular Regular de Problemas Filosóficos y de Antropología Filosófica (Universidad de Morón). Coordinadora académica de la Cátedra Abierta de Estudios de Género (Universidad de Morón). Ex Directora de la carrera de Filosofía (Universidad de Morón). Profesora Titular de Filosofía Antigua y Problemas Especiales de Filosofía Antigua (Universidad Nacional de Mar del Plata). Investigadora principal por la Universidad de Morón. Autora de Hesíodo. Una Introducción crítica, Bs. As., 2005, Homero. Una introducción crítica, Bs. As., 2005, Foucault y lo político, Bs. As., 2009. Hesíodo. Discurso y Linaje. Una aproximación arqueológica, Mar del Plata, 2016. Profesora invitada en universidades nacionales y extranjeras. Autora de numerosas publicaciones en revistas nacionales y extranjeras.

\section{BIBLIOGRAFÍA}

Hesíodo (2000). Obras y fragmentos. Madrid: Gredos.

Hesiod (2006). Theogony. Works and Days. Testimonia. G. W. Most, (editor y traductor). Loeb Classical Library. London: Harvard University Press.

Liddel, H. G. y Scott, R. (1996). A Greek-English Lexicon. Oxford: Clarendon Press.

Hesíodo (2005). Teogonía, Trabajos y Días. L. Liñares, introducción, traducción y notas. Edición bilingüe. Buenos Aires: Losada.

Vianello de Córdova, P. (1978). Hesiodo Teogonía. México: Universidad Nacional Autónoma de México.

Buber, M. (1974). Yo y tú. Buenos Aires: Nueva Visión.

Heidegger, M. (1997). Ser y tiempo. Santiago de Chile: Editorial Universitaria.

Madrid, M. (1999). La misoginia en Grecia. Valencia: Cátedra.

Mounier, E. (1972). El personalismo. Buenos Aires: EUDEBA. 